\title{
Should lower risk patients with ductal carcinoma in situ be treated with adjuvant whole breast radiotherapy, after breast conservation surgery?
}

Jessamy Bagenal, , senior medical editor, The Lancet,${ }^{1}$ Nicola Roche, consultant breast surgeon, ${ }^{1}$ Gill Ross, consultant clinical oncologist, ${ }^{1}$ Anna Kirby, consultant clinical oncologist, ${ }^{1}$ David Dodwell, consultant clinical oncologist ${ }^{2}$

1. The Royal Marsden Hospital, London, UK

2. Nuffield Department of Population Health, University of Oxford, Oxford, UK

Correspondence to J Bagenal jessamy.bagenal@googlemail.com

\section{What you need to know}

- Women with ductal carcinoma in situ are usually offered breast conserving surgery (BCS), often followed by whole breast radiotherapy (WBRT).

- WBRT reduces ipsilateral breast events but has not been shown [because of an absence of evidence?] to improve breast cancer specific or overall mortality.

- Patients will have different perceptions of the risks and benefits of WBRT and should be assisted in their decision making by clear presentation of the information.

Ductal carcinoma in situ (DCIS) affects around 8000 women per year in the UK. ${ }^{1}$ Since the introduction of mammography screening, the incidence of DCIS has increased and now represents around $20 \%$ of all new screen detected breast cancers. ${ }^{2}$

Ductal carcinoma is categorised into low, intermediate and high grade based on histological features by a pathologist. Most cases of DCIS are treated with breast conserving surgery (BCS), often followed by whole breast radiotherapy (WBRT). An individual patient level meta-analysis (four randomised controlled trials, 3729 women) found that WBRT approximately halved the rate of ipsilateral DCIS or invasive recurrence at 10 years compared with no radiotherapy following BCS. ${ }^{3}$ However, WBRT can cause side effects such as impaired cosmesis, skin changes, and late cardiac toxicity. ${ }^{i}$ Patients might also find WBRT inconvenient and expensive. National Institute of Health and Care Excellence (NICE) guidelines recommend offering WBRT to all patients with DCIS. ${ }^{4}$ The European Society of Medical Oncology guidelines suggest that WBRT might be omitted in some low risk patients. $^{5}$

However, observational studies done in the UK, US, and Europe note wide variations in the delivery of adjuvant radiotherapy in these patients. ${ }^{6}$ This variation possibly reflects uncertainty as to whether the benefits of WBRT are large enough to warrant blanket use of adjuvant WBRT or whether WBRT can be safely omitted in a subset of lower risk patients. 


\section{In this article we discuss the evidence surrounding radiotherapy use in DCIS. What is the evidence of uncertainty?}

\section{Search strategy}

We searched the Cochrane Library (including the Cochrane Central Database of Controlled Trials), Ovid Medline, and clinical trial registers (clinicaltrials.gov, controlled-trials.com, who.int/trialsearch), PROSPERO, National Cancer Research Institute portfolio, Cancer Research UK, and Macmillan websites from 1990 until May 2017. We also cross referenced bibliographies. We ran multiple searches using the terms:

"Ductal carcincoma", "DCIS" AND "RADIOTHERAPY", "DCIS" AND "Treatment" in combination and alone. We selected manuscripts and trials that were most relevant to the article through discussion between the authors.

\section{What is the risk of an ipsilateral breast event in a DCIS patient?}

Evidence from three prospective studies in patients with DCIS who have undergone BCS suggests that the risk of an ipsilateral breast event continues to rise with time. ${ }^{78}$ Studies have failed to identify a sufficiently low risk group of patients that gain no appreciable benefit in terms of reduced risk of recurrence from WBRT In a trial with 636 women with low or intermediate grade DCIS, the ipsilateral event rate was $0.9 \%$ in the WBRT arm versus $6.7 \%$ in the observation arm (hazard ratio, $0.11 ; 95 \%$ confidence interval, 0.03 to $0.47 ; \mathrm{P}$ $<.001){ }^{7}$ A trial in 158 women with low and intermediate grade DCIS closed early as the ipsilateral breast events met the predetermined stopping rules with an ipsilateral breast event rate of $2.4 \%$ per patient-year. ${ }^{8}$ In another trial, the risk of an ipsilateral breast event at 12 years was $14.4 \%$ for the low-intermediate grade group (561 women) and $24.6 \%$ for the high grade group (104 women). ${ }^{9}$ Patients might have differing opinions on an acceptable rate of an ipsilateral breast event.

Scoring systems have been developed to predict the risk of local recurrence in an attempt to identify patients at low risk of recurrence who may be able to avoid WBRT and thereby guide adjuvant therapy recommendations (table 1). However, these recommendations are used variably in practice as they do not provide sufficiently precise estimates of the risk of local relapse.

Table 1 Predictive scoring systems in DCIS [Online only]

\begin{tabular}{lcccc}
\hline Score & Features & Validation & Analysis & $\begin{array}{c}\text { Results of } \\
\text { validation }\end{array}$ \\
\hline $\begin{array}{l}\text { Modified University } \\
\text { of Southern } \\
\text { California/Van Nuys } \\
\text { Prognostic Index }\end{array}$ & $\begin{array}{c}\text { Four } \\
\text { clinicopathological } \\
\text { features (age, tumour } \\
\text { size, margin width, } \\
\text { pathologic } \\
\text { classification) }\end{array}$ & $\begin{array}{c}\text { Prospective } \\
\text { database } \\
\text { validated on } 706 \\
\text { women }\end{array}$ & $\begin{array}{c}\text { Multivariate } \\
\text { analysis to } \\
\text { derive formula }\end{array}$ & $\begin{array}{c}\text { No difference in 12 year } \\
\text { local recurrence free } \\
\text { survival in DCIS }\end{array}$ \\
& & & $\begin{array}{c}\text { patients who scored as } \\
\text { low risk on the Van } \\
\text { Nuys Prognostic Index }\end{array}$ \\
& & & $\begin{array}{c}\text { regardless of whether or } \\
\text { not they were treated } \\
\text { with WBRT }\end{array}$
\end{tabular}


Sloane Kettering

Memorial

Nomogram

DCIS score
10 clinic-pathological, and treatment variables to estimate the probability of 10 year local recurrence (age, family history, presentation, nuclear grade, necrosis, surgical margins, number of surgeries, year of surgery, adjuvant radiotherapy, adjuvant endocrine [therapy?]) Yes Genomic profile calculated from seven cancer related genes and five reference genes
Retrospective validation on 1868 women

327 tissue
samples from
registration trial
designed to find
a subset of
DCIS patients
for whom
WBRT was not
necessary.
718 tissue
samples from
established
population
based cohort
diagnosed with
DCIS and
treated with
BCS

Multivariate

Cox

proportional hazards model

Association of DCIS score analysed with risk of ipsilateral breast event using Cox regression analysis.

Cox modelling used to assess relationship between independent covariates, the DCIS score, and local recurrence
DCIS nomogram for prediction of 5- and 10year ipsilateral breast event probabilities

showed good calibration and discrimination, with a concordance index of 0.704 (bootstrap corrected, 0.688) and a concordance probability estimate of 0.686 .

The continuous DCIS score was statistically significantly associated with the risk of developing an ipsilateral breast event (hazard ratio $=2.31,95 \%$ confidence interval $=$ 1.15 to $4.49 ; \mathrm{P}=0.02$ ) when adjusted for tamoxifen use (prespecified primary analysis) and with invasive breast events (unadjusted hazard ratio $=3.68,95 \%$ confidence interval $=1.34$ to 9.62 ; $\mathrm{P}=0.01)$

DCIS score provided independent information on local recurrence beyond clinical pathological features

\section{Effect of WBRT on overall or breast cancer specific mortality}

Although WBRT has been shown to decrease the risk of ipsilateral local (within-breast)

recurrence by around $50 \%$, it has not been shown to improve breast cancer mortality. ${ }^{11}{ }^{12}$ The evidence from five randomised controlled trials in women with DCIS suggests that WBRT did not influence breast cancer mortality or overall survival (table 2). The individual patientlevel meta-analysis reported a 10 year breast cancer mortality of around $4 \% .^{3}$ so a very large study would be required to show a small reduction in breast cancer mortality from WBRT. Similarly, recent large population-based longitudinal studies find insufficient benefit of WBRT in reducing breast cancer specific mortality at 10 and 20 years to warrant its use in all patients. $^{12} 14$

A recent study analysed 10 and 20 year breast cancer specific mortality using the Surveillance Epidemiology and End Results (SEER) data (18 registries, 108196 women with 
DCIS). Invasive recurrence increased the risk of dying from breast cancer (hazard ration $18.1,95 \%$ confidence interval 14.0-23.6; $\mathrm{P}<0.001$ ), but the prevention of recurrence by WBRT did not diminish breast cancer specific mortality at 10 years. ${ }^{12}$ It is not possible to identify and account for the potential confounding factors in a study of this type, but these results suggest that any increased mortality risk from an invasive recurrence is unlikely to be great enough to warrant WBRT.

Table 2

Another large population-based longitudinal study also used SEER data ${ }^{14}$ to study breast cancer specific mortality after BCS alone and in patients who received BCS and WBRT. The study used a patient prognostic scoring model comprising clinical and pathological features for risk stratification and propensity scoring to address possible confounding. In this cohort of 32144 women, breast cancer mortality rate was $0.9 \%$. The 10 year breast cancer mortality rate was $1.8 \%$ in the WBRT group and $2.1 \%$ in the non-WBRT group (absolute difference, $0.3 \%$; log-rank test, $\mathrm{P}=0.003$; hazard ratio, $0.73 ; 95 \%$ confidence interval, 0.62 to 0.88 ). However, the hazard ratios depicting the apparent effect of WBRT for each of the defined prognostic groups had wide confidence intervals, and a causal relationship between WBRT and reduced breast cancer mortality cannot be confirmed.

Any small benefit derived from WBRT in breast cancer specific mortality, if this exists, must be appreciated in the context that patients are more likely to die of other causes than those related to breast cancer. ${ }^{14}$

\section{Is ongoing research likely to provide relevant evidence?}

We searched clinical trial registries and found three large studies that might shed light on some of the uncertainty around the use of radiotherapy in patients with DCIS. The two largest trials aim to identify low risk DCIS patients based on clinical and pathological factors and compare active surveillance with standard therapy (breast conserving surgery and WBRT) using 10 year rate of invasive local recurrence as an endpoint ${ }^{15}$ (table 3). The smaller "Forget me not" cohort is part of a larger database and will report outcomes for women who did not have surgery for DCIS These studies should help to elucidate the natural history of DCIS and how to identify patients with a low risk of invasive recurrence.

Table 3 New trials

\begin{tabular}{lllccccc}
\hline $\begin{array}{l}\text { Trial } \\
\text { name }\end{array}$ & Location & Design & Population & $\begin{array}{c}\text { Intervent } \\
\text { ion }\end{array}$ & $\begin{array}{c}\text { Compar } \\
\text { ator }\end{array}$ & $\begin{array}{c}\text { Outcom } \\
\text { e }\end{array}$ & $\begin{array}{c}\text { Expecte } \\
\text { d results }\end{array}$ \\
\hline Low & International & Prospective & 1240 women & Active & Standard & 10 year & 2029
\end{tabular}




\begin{tabular}{|c|c|c|c|c|c|c|c|}
\hline $\begin{array}{l}\text { risk } \\
\text { DCIS } \\
\text { LORD }\end{array}$ & , multicentre & $\begin{array}{l}\text { open label } \\
\text { randomised } \\
\text { phase III } \\
\text { non- } \\
\text { inferiority } \\
\text { trial }\end{array}$ & $\begin{array}{c}>45 \text { with } \\
\text { screen } \\
\text { detected } \\
\text { asymptomatic } \\
\text { pure low } \\
\text { grade DCIS } \\
\text { on vacuum } \\
\text { biopsy }\end{array}$ & surveillance & $\begin{array}{l}\text { treatment } \\
\text { for DCIS }\end{array}$ & $\begin{array}{l}\text { ipsilateral } \\
\text { breast } \\
\text { cancer } \\
\text { free } \\
\text { percentage }\end{array}$ & \\
\hline $\begin{array}{l}\text { Low } \\
\text { risk } \\
\text { DCIS } \\
\text { Trial } \\
\text { LORIS }\end{array}$ & $\begin{array}{l}\text { Multi centre } \\
\text { UK based }\end{array}$ & $\begin{array}{l}\text { Prospective } \\
\text { randomised } \\
\text { controlled } \\
\text { phase III non } \\
\text { inferiority } \\
\text { trial }\end{array}$ & $\begin{array}{c}932>46 \\
\text { screen } \\
\text { detected } \\
\text { asymptomatic } \\
\text { pure non- } \\
\text { high grade } \\
\text { DCIS }\end{array}$ & $\begin{array}{c}\text { Active } \\
\text { surveillance }\end{array}$ & Surgery & $\begin{array}{l}10 \text { year } \\
\text { ipsilateral } \\
\text { invasive } \\
\text { breast } \\
\text { cancer } \\
\text { free } \\
\text { survival } \\
\text { time }\end{array}$ & 2024 \\
\hline $\begin{array}{l}\text { Forget } \\
\text { me not }\end{array}$ & $\begin{array}{l}\text { Multicentre, } \\
\text { UK based }\end{array}$ & $\begin{array}{l}\text { Retrospective } \\
\text { cohort }\end{array}$ & $\begin{array}{c}\text { DCIS } \\
\text { patients not } \\
\text { treated with } \\
\text { surgery or } \\
\text { who } \\
\text { underwent } \\
\text { significant } \\
\text { [Looks } \\
\text { incomplete. } \\
\text { What does } \\
\text { this mean?] } \\
\text { (over 12 } \\
\text { months) in } \\
\text { surgical } \\
\text { treatment }\end{array}$ & & & & $\begin{array}{l}\text { Results } \\
\text { released at } \\
\text { time of } \\
\text { publication } \\
\text { [Can these } \\
\text { be } \\
\text { included if } \\
\text { relevant?] }\end{array}$ \\
\hline
\end{tabular}

\section{What to do in the light of the uncertainty?}

The benefit of WBRT in many cases is small, and patients who wish to avoid WBRT can be supported and reassured in this decision. Discuss the uncertainty over the risks and benefits of WBRT treatment with patients fully. It is likely that a subset of patients does not need WBRT, but we have yet to develop the best way to identify this group. ${ }^{5}$ A reasonable approach is to risk stratify patients using one of the scoring systems in table 1. Table 4 lists clinical and pathological features shown to be associated with recurrence. Where possible, use shared decision making aids to help the conversation with patients. ${ }^{16}$ Offer counselling with specialist nurses and provide information leaflets that display all treatment options.

Table 4 Clinical pathological features found to be associated with recurrence

\section{Feature}

Young age

Symptomatic

presentation

Family history

Multifocality

\section{Evidence}

High quality: analysis from one randomised trial and large well conducted observational studies ${ }^{17} 1819$

High quality: analysis from two randomised trials ${ }^{120}$

Low quality: small retrospective cohort study ${ }^{21}$

High/moderate quality: large retrospective cohort studies ${ }^{22}$ and central pathology review of patients entered into randomised trial ${ }^{23}$ 
Size

Margin status

Volume of disease at closest margin

Nuclear grade

Presence of comedo necrosis

Architectural pattern
High/moderate quality: large retrospective cohort studies ${ }^{24}$ and central pathology review of patients entered into randomised trial ${ }^{23}$

High quality: analysis from three randomised trials and retrospective study of pathological samples ${ }^{125} 26$

Moderate quality - one retrospective cohort study ${ }^{27}$

High quality: analysis from randomised trial ${ }^{1}$ and case cohort study within a randomised trial $^{28}$

High quality: analysis from randomised trial ${ }^{29}$ case cohort study within a randomised trial ${ }^{28}$ and and central pathology review of patients entered into randomised trial $^{7}$

High quality: analysis from randomised trial ${ }^{1}$ and central pathology review of patients entered into randomised trial ${ }^{23}$

\section{What patients need to know?}

- Ductal carcinoma in situ very rarely leads to death.

- Most DCIS is treated with breast conserving surgery (BCS), often followed by whole breast radiotherapy (WBRT).

- WBRT reduces the risk of recurrence, but WBRT does not reduce the risk of dying from breast cancer or improve overall survival.

- You should expect your doctor to advise you on the likely benefits and risks of radiotherapy, taking into consideration the severity of your disease, and accepting that there is some uncertainty about the benefits of treatment.

- Because of this uncertainty, you might wish to explore what type of treatment is best for you based on your personal risk tolerance and life expectancy.

\section{Recommendations for future research}

- Development of better predictive markers/tools to identify a group of patients in whom WBRT can be safely omitted

- Explore how current evidence is understood by clinicians and delivered to patients to reduce geographical variations in the proportion of patients being offered WBRT

- Explore how patients feel about making decisions around WBRT

\section{Education into Practice}

How has reading this article changed the way you might approach discussions of radiotherapy with patients with DCIS?

How might you better support patients who have received a diagnosis of DCIS?

\section{How patients were involved in the creation of this article}

A draft manuscript was reviewed by representatives of ICPV. They were happy with the overall manuscript but had specific statements about what a patient can expect from their doctor and this was addressed in the what patients need to know box.. A patient with DCIS kindly reviewed this paper. She endorsed the uncertainty around appropriate treatment for DCIS and that medical professionals must recognise that patients have different personal risk tolerances. We have emphasised this and suggest that doctors discuss the risk and benefits of WBRT and assist patients in making a shared decision.

Provenance and peer review: Commissioned, based on an idea from the author; externally peer reviewed.

Conflicts of interest statement: We have read and agreed to the BMJs conflict of interest policy. JB was a clinical editor at BMJ from 2015-2017. 
1. Breast cancer statistics, Cancer Research UK. http://www.cancerresearchuk.org/healthprofessional/cancer-statistics/statistics-by-cancer-type/breast-cancer\#heading-One.

2. Martínez-Pérez C, Turnbull AK, Ekatah GE, et al. Current treatment trends and the need for better predictive tools in the management of ductal carcinoma in situ of the breast. Cancer Treat Rev. 2017;55:163-172.

3. Early Breast Cancer Trialists' Collaborative Group (EBCTCG), Correa C, McGale P, et al. Overview of the Randomised trials of radiotherapy in ductal carcinoma in situ of the breast. JNCI Monogr. 2010;41:162-77.

4. Early and locally advanced breast cancer: diagnosis and treatment. Guidance and guidelines. National Institute for Health and Care Excellence.

https://www.nice.org.uk/guidance/cg80.

5. Senkus E, Kyriakides S, Penault-Llorca F, et al. Primary breast cancer: ESMO Clinical Practice Guidelines for diagnosis, treatment and follow-up. Ann Oncol. 2013;24(suppl 6):vi723.

6. Smith GL, Buchholz TA. Radiotherapy following breast-conserving surgery for screendetected ductal carcinoma in situ: indications and utilisation in the UK. Interim findings from the Sloane Project. Breast Dis. 2008;19(2):168.

7. McCormick B, Winter K, Hudis C, et al. RTOG 9804: A prospective randomised trial for good-risk ductal carcinoma in situ comparing radiotherapy with observation. J Clin Oncol 2015;33:709-15.

8. Wong JS, Kaelin CM, Troyan SL, et al. Prospective study of wide excision alone for ductal carcinoma in situ of the breast. J Clin Oncol 2006;24:1031-6.

9. Solin LJ, Gray R, Hughes LL, et al. Surgical excision without radiation for ductal carcinoma in situ of the breast: 12-year results from the ECOG-ACRIN E5194 Study. J Clin Oncol 2015;33:3938-44.

10. Lagios MD, Silverstein MJ. Ductal carcinoma in situ: Recent history and areas of controversy. Breast J. 2015;21(1):21-26. doi:10.1111/tbj.12359

11. Wapnir IL, Dignam JJ, Fisher B, et al. Long-Term outcomes of invasive ipsilateral breast tumor recurrences after lumpectomy in NSABP B-17 and B-24 randomized clinical trials for DCIS. JNCI J Natl Cancer Inst 2011;103:478-88.

12. Narod SA, Iqbal J, Giannakeas V, Sopik V, Sun P. Breast cancer mortality after a diagnosis of ductal carcinoma in situ. JAMA Oncol 2015;1:888.

14. Sagara Y, Freedman RA, Vaz-Luis I, et al. Patient prognostic score and associations with survival improvement offered by radiotherapy after breast-conserving surgery for ductal carcinoma in situ: a population-based longitudinal cohort study. J Clin Oncol 2016;34:11906.

15. Elshof LE, Tryfonidis K, Slaets L, et al. Feasibility of a prospective, randomised, openlabel, international multicentre, phase III, non-inferiority trial to assess the safety of active surveillance for low risk ductal carcinoma in situ - The LORD study. Eur J Cancer 2015;51:1497-510.

16. Ozanne EM, Schneider KH, Soeteman D, et al. onlineDeCISion.org: a web-based decision aid for DCIS treatment. Breast Cancer Res Treat. 2015;154:181-90.

17. EORTC Breast Cancer Cooperative Group N, EORTC Radiotherapy Group P, Bijker N, et al. Breast-conserving treatment with or without radiotherapy in ductal carcinoma-in-situ: ten-year results of European Organisation for Research and Treatment of Cancer randomized phase III trial 10853--a study by the EORTC Breast Cancer Cooperative Group and EORTC Radiotherapy Group. J Clin Oncol 2006;24:3381-7.

18. Van Zee KJ, Liberman L, Samli B, et al. Long term follow-up of women with ductal 
carcinoma in situ treated with breast-conserving surgery: the effect of age. Cancer 1999;86:1757-67.

19. Vicini FA, Kestin LL, Goldstein NS, et al. Impact of young age on outcome in patients with ductal carcinoma-in-situ treated with breast-conserving therapy. J Clin Oncol 2000;18:296-306.

20. Fisher B, Dignam J, Wolmark N, et al. Tamoxifen in treatment of intraductal breast cancer: National Surgical Adjuvant Breast and Bowel Project B-24 randomised controlled trial. Lancet 1999;353:1993-2000.

21. Hiramatsu H, Bornstein BA, Recht A, et al. Local recurrence after conservative surgery and radiation therapy for ductal carcinoma in situ: Possible importance of family history. Cancer J Sci Am 1:55-61.

22. Rakovitch E, Pignol J-P, Hanna W, et al. Significance of multifocality in ductal carcinoma in situ: outcomes of women treated with breast-conserving therapy. J Clin Oncol 2007;25:5591-6.

23. Fisher ER, Land SR, Saad RS, et al. Pathologic variables predictive of breast events in patients with ductal carcinoma in situ. Am J Clin Pathol. 2007;128:86-91.

24. Silverstein MJ. The University of Southern California/Van Nuys prognostic index for ductal carcinoma in situ of the breast. Am J Surg. 2003;186(4):337-343. http://www.ncbi.nlm.nih.gov/pubmed/14553846. Accessed July 13, 2017.

25. Fisher B, Land S, Mamounas E, Dignam J, Fisher ER, Wolmark N. Prevention of invasive breast cancer in women with ductal carcinoma in situ: an update of the National Surgical Adjuvant Breast and Bowel Project experience. Semin Oncol 2001;28:400-18. 26. Silverstein MJ, Lagios MD, Groshen $S$, et al. The influence of margin width on local control of ductal carcinoma in situ of the breast. N Engl J Med. 1999;340:1455-61.

27. Rudloff U, Brogi E, Reiner AS, et al. The influence of margin width and volume of disease near margin on benefit of radiation therapy for women with DCIS treated with breastconserving therapy. Ann Surg 2010;251:583-91.

28. Ringberg A, Nordgren H, Thorstensson S, et al. Histopathological risk factors for ipsilateral breast events after breast conserving treatment for ductal carcinoma in situ of the breast--results from the Swedish randomised trial. Eur J Cancer 2007;43:291-98.

29. Fisher ER, Dignam J, Tan-Chiu E, et al. Pathologic findings from the National Surgical Adjuvant Breast Project (NSABP) eight-year update of Protocol B-17: intraductal carcinoma. Cancer 1999;86:429-38.

30. Wärnberg F, Garmo H, Emdin S, et al. Effect of radiotherapy after breast-conserving surgery for ductal carcinoma in situ: 20 years follow-up in the randomized SweDCIS trial. $J$ Clin Oncol 2014;32:3613-8.

31. Donker M, Litière S, Werutsky G, et al. Breast-conserving treatment with or without radiotherapy in ductal carcinoma In Situ: 15-year recurrence rates and outcome after a recurrence, from the EORTC 10853 randomized phase III trial. J Clin Oncol 2013;31:4054-9. 32. Cuzick J, Sestak I, Pinder SE, et al. Effect of tamoxifen and radiotherapy in women with locally excised ductal carcinoma in situ: long-term results from the UK/ANZ DCIS trial. Lancet Oncol 2011;12:21-9. 